\title{
Illuminating the mutational spectrum of pediatric myeloproliferative neoplasms
}

\author{
Stephen E. Langabeer* \\ Cancer Molecular Diagnostics, St. James's Hospital, Dublin, Ireland
}

The myeloproliferative neoplasms (MPN) are clonal, hematopoietic stem cell-derived diseases characterised by bone marrow proliferation of one or more of the myeloid cell lineages with the main subtypes being polycythemia vera (PV), essential thrombocythemia (ET), and primary myelofibrosis (PMF). The diagnosis and classification of these diseases is dependent on clinical, hematological, histo-morphological and increasingly, on molecular genetic findings [1]. In adults, the most commonly acquired mutation associated with MPN is the JAK2 V617F, occurring in $>95 \%$ of PV cases and in $50-60 \%$ of ET and PMF patients. This mutation disrupts the function of the intracellular JAK2 molecule that is required for normal hematopoietic cytokine signalling and has become a target for therapeutic intervention [2]. Alternative mutations of JAK2 within exon 12 can be detected in the majority of those remaining V617F-negative PV patients [3]. Several other genetic abnormalities have been described in MPN which occur at a much lower frequency than the JAK2 V617F. Mutations in MPL exon 10, which encodes the receptor for thrombopoietin, a major regulator of megakaryocyte and platelet development, are present in approximately $5 \%$ and $3 \%$ of PMF and ET patients respectively [4]. Recent whole exome sequencing studies of adult MPN patients have led to the discovery of insertion and/or deletion mutations in exon 9 of CALR, a gene that encodes the endoplasmic reticulum-associated, calcium binding protein, calreticulin. These disease driving mutations of CALR result in a frame shift of the coding sequence, altered amino acid composition of the translated protein, and loss of the endoplasmic reticulum retention motif. CALR mutations do not occur in PV patients but are present in up to $80 \%$ of ET and PMF patients who are JAK2 V617F-and MPL-mutation negative [5]. Approximately 10\% of adult ET and PMF patients have no evidence of these three driver mutation types and are termed "triple-negative" MPN. Supplementary "passenger" mutations may be acquired that can influence the initiation and evolution of the disease, however these mutations are not specific for MPN as they are also present in other myeloid malignancies such as myelodysplastic syndromes and acute myeloid leukemia [6].

Sporadic MPN are uncommon in children with an incidence approximately one hundred fold lower than that of adults suggesting an alternative aetiology of the disease in such cases [7,8]. In childhood MPN, the prevalence of the JAK2 V617F mutation is lower when compared to that in adults [9-11] with acquired mutations of MPL exceedingly rare [12]. Analysis of the more recently described CALR mutations in pediatric MPN cohorts has also revealed significantly lower mutation rates than in adult MPN, inferring differences in the molecular pathogenesis of these diseases in childhood [13,14]. Furthermore, the relatively high proportion of pediatric cases without evidence of one the three driver mutation types associated with adult MPN suggests such cases may not be clonal malignancies: this has significant implications for therapeutic intervention with cytoreductive agents [15].

Shedding further light on this issue, several groups have recently applied targeted sequencing of large panels of either myeloid- or cancer-associated genes to pediatric MPN, especially ET patients [1618] with each of these contemporary studies revealing insights into the mutational spectrum with the results summarized in Table 1 . Karow et al. [16] analysed 43 pediatric MPN patients, most of whom had ET, by using capture-based targeted next-generation sequencing to simultaneously search for mutations in 104 hematopoietic malignancyassociated genes. The JAK2 V617F and CALR mutations were found most frequently, however the frequency of mutations in genes implicated in epigenetic regulation (ASXL1, DNMT3A, EZH2, IDH1, and TET2) was significantly lower than that of $25 \%$ observed in adult MPN. Confirming previous studies, $30 \%$ of patients had no evidence of mutations in MPN-associated genes. A second study of 25 childhood ET cases employed targeted sequencing of 55 genes associated with myeloid malignancy [17]. Again JAK2 and CALR mutations were less frequent than in adult cohorts but somewhat conversely, ASXL1 mutations were demonstrated in four cases (Table 1). Lastly, using a targeted deep sequencing assay of 585 cancer-related genes in five characterized childhood ET patients, Kucine et al. [18] identified mutations, in addition to the JAK2 V617F, in genes involved in transcriptional regulation (NUP98, MED12, AR, and CEBPA) (Table 1). Noticeably, each of these examinations has identified mutated cooperating genes but with minimal inter-study cross-over, possibly representing differences in methodological approach and the size of the gene panels utilised.

An interesting observation from these latter three studies is the high rate of co-occurrence of mutations in pediatric ET which suggests that children may have a more complex disease than adults thus reflecting an unstable genetic background: rapid acquisition of these mutations may account for the early onset of ET in children. While these approaches are highly informative and have the capability to identify targets that may be clinically actionable, these exon sequencing approaches may fail to identify abnormalities in non-coding regions. Sequencing of the 5' untranslated region of THPO, the gene that encodes the hormone

Correspondence to: Stephen E. Langabeer, $\mathrm{PhD}$, Cancer Molecular Diagnostics, Central Pathology Laboratory, St. James's Hospital, Dublin 8, Ireland, Tel: +353 1 4103576, Fax: +353 1 4103513, E-mail: slangabeer@stjames.ie

Key words: pediatric, myeloproliferative neoplasm, mutations, targeted sequencing Received: August 14, 2016; Accepted: August 25, 2016; Published: August 27, 2016 
Table 1. Mutations identified by targeted sequencing in pediatric myeloproliferative neoplasms [16-18]. ET: essential thrombocythemia; PV: polycythemia vera.

\begin{tabular}{|c|c|c|c|c|}
\hline \multirow[t]{2}{*}{ Gene } & \multicolumn{4}{|c|}{ Mutation frequency } \\
\hline & $\begin{array}{l}\text { Karow et al. } \\
{[16]} \\
\text { ET }(n=41)\end{array}$ & $P V(n=2)$ & $\begin{array}{l}\text { Fu et al. }[17] \\
\text { ET }(n=25)\end{array}$ & $\begin{array}{l}\text { Kucine et al. } \\
{[18]} \\
\text { ET }(n=5)\end{array}$ \\
\hline$J A K 2 \mathrm{~V} 617 \mathrm{~F}$ & $8(19.5 \%)$ & $2(100 \%)$ & $6(24.0 \%)$ & $3(60.0 \%)$ \\
\hline CALR & $4(9.8 \%)$ & - & $1(4.0 \%)$ & - \\
\hline$M P L$ & $1(2.4 \%)$ & - & - & - \\
\hline IRF8 & $4(9.8 \%)$ & - & - & - \\
\hline$A S X L 1$ & - & - & $4(16.0 \%)$ & - \\
\hline NUP98 & - & - & - & $3(60.0 \%)$ \\
\hline$C U X 1$ & $2(4.9 \%)$ & - & - & - \\
\hline DNMT3A & $2(4.9 \%)$ & - & - & - \\
\hline EP300 & $2(4.9 \%)$ & - & - & - \\
\hline EPOR & $2(4.9 \%)$ & - & - & - \\
\hline$M Y B$ & $2(4.9 \%)$ & - & - & - \\
\hline$N F 1$ & $2(4.9 \%)$ & - & - & - \\
\hline PTPRT & $2(4.9 \%)$ & - & - & - \\
\hline MED12 & - & - & - & $2(40.0 \%)$ \\
\hline PAX5 & - & - & - & $2(40.0 \%)$ \\
\hline$A R 2$ & - & - & - & $2(40.0 \%)$ \\
\hline AKT3 & $1(2.4 \%)$ & - & - & - \\
\hline$F O X P 1$ & $1(2.4 \%)$ & - & - & - \\
\hline$I D H I$ & $1(2.4 \%)$ & - & - & - \\
\hline IFI30 & $1(2.4 \%)$ & - & - & - \\
\hline$J A K 2$ & $1(2.4 \%)$ & - & $2(8.0 \%)$ & - \\
\hline PIK $3 A P I$ & $1(2.4 \%)$ & - & - & - \\
\hline PIK $3 C 2 A$ & $1(2.4 \%)$ & - & - & - \\
\hline$R B L 2$ & $1(2.4 \%)$ & - & - & - \\
\hline $\mathrm{SH} 2 \mathrm{~B} 3$ & $1(2.4 \%)$ & - & $1(4.0 \%)$ & - \\
\hline FLT3 & - & - & $1(4.0 \%)$ & - \\
\hline$U 2 A F 1$ & - & - & $1(4.0 \%)$ & - \\
\hline NRAS & - & - & $1(4.0 \%)$ & - \\
\hline$M L L$ & - & - & $1(4.0 \%)$ & - \\
\hline$G N A S$ & - & - & $1(4.0 \%)$ & - \\
\hline$R U N X 1$ & - & - & $1(4.0 \%)$ & - \\
\hline WT1 & - & - & $1(4.0 \%)$ & - \\
\hline ZRSR2 & - & - & $1(4.0 \%)$ & - \\
\hline STAT5B & - & - & $1(4.0 \%)$ & - \\
\hline CEBPA & - & - & - & $1(20.0 \%)$ \\
\hline TERT & - & - & - & $1(20.0 \%)$ \\
\hline$K R A S$ & - & $1(2.4 \%)$ & - & - \\
\hline PTPN11 & - & $1(2.4 \%)$ & - & - \\
\hline TET2 & - & $1(2.4 \%)$ & - & - \\
\hline
\end{tabular}

thrombopoietin which controls platelet production, has recently been shown to be of diagnostic value [19].

In conclusion, targeted sequencing of pediatric MPN patients has revealed some of the underlying complexity of co-operating mutations however these investigations will require confirmation in extended cohorts with functional validation of mutations. It must be remembered that the pathogenesis of MPN is not entirely dependent on genetic abnormalities but other causes, such as inflammation, are likely to play a major role [20]. The next World Health Organization classification of MPN is likely to include the presence of a clonal marker other than a JAK2, MPL, or CALR mutation as a minor criterion for diagnosis of ET or PMF [21], expediting the adoption of a targeted exon sequencing approach for a molecular genetic diagnosis.

\section{References}

1. Tefferi A (2015) Myeloproliferative neoplasms: a contemporary review. JAMA Oncol

\section{1: 97-105. [Crossref]}

2. Gäbler K, Behrmann I, Haan C (2013) JAK2 mutants (e.g., JAK2V617F) and their importance as drug targets in myeloproliferative neoplasms. JAKSTAT 2: e25025. [Crossref]

3. Scott LM, Tong W, Levine RL, Scott MA, Beer PA, et al. (2007) JAK2 exon 12 mutations in polycythemiavera and idiopathic erythrocytosis. $N$ Engl J Med 356: 459468.[Crossref]

4. Pardanani AD, Levine RL, Lasho T, Pikman Y, Mesa RA, et al. (2006) MPL515 mutations in myeloproliferative and other myeloid disorders: a study of 1182 patients. Blood 108: 3472-3476.[Crossref]

5. Cazzola M, Kralovics R (2014) From Janus kinase 2 to calreticulin: the clinically relevant genomic landscape of myeloproliferative neoplasms. Blood 126: 3714-3719. [Crossref]

6. Langabeer SE, Andrikovics H, Asp J, Bellosillo B, Carillo S, et al. (2015) Molecular diagnostics of myeloproliferative neoplasms. Eur J Haematol 95: 270-279.[Crossref]

7. Teofili L, Foa R, Giona F, Larocca LM (2008) Childhood polycythemiavera and essential thrombocythemia: does their pathogenesis overlap with that of adult patients? Haematologica 93: 169-172. [Crossref]

8. Kucine N, Chastain KM, Mahler MB, Bussel JB (2014) Primary thrombocytosis in children. Haematologica 99: 620-628.[Crossref]

9. Giona F, Teofili L, Moleti ML, Martini M, Palumbo G, et al. (2012) Thrombocythemia and polycythemia in patients younger than 20 years at diagnosis: clinical and biologic features, treatment, and long-term outcome. Blood 119: 2219-2227.[Crossref]

10. Ismael O, Shimada A, Hama A, Sakaguchi H, Doisaki S, et al. (2012) Mutations profile of polycythemiavera and essential thrombocythemia among Japanese children. Pediatr Blood Cancer 59: 530-535.[Crossref]

11. DeLario MR, Sheehan AM, Ataya R, Bertuch AA, Vega C 2nd, et al. (2012) Clinical, histopathologic, and genetic features of pediatric primary myelofibrosis--an entity different from adults. Am J Hematol 87: 461-464.[Crossref]

12. Farruggia P, D'Angelo P, La Rosa M, Scibetta N, Santangelo G, et al. (2013) MPL W515L mutation in pediatric essential thrombocythemia. Pediatr Blood Cancer 60: E52-54.[Crossref]

13. Langabeer SE, Haslam K, McMahon C (2014) CALR mutations are rare in childhood essential thrombocythemia. Pediatr Blood Cancer 61: 1523.[Crossref]

14. Giona F, Teofili L, Capodimonti S, Laurino M, Martini M, et al. (2014) CALR mutations in patients with essential thrombocythemia diagnosed in childhood and adolescence. Blood 123: 3677-3679. [Crossref]

15. Randi ML, Geranio G, Bertozzi I, Micalizzi C, Ramenghi U, et al. (2015) Are all cases of paediatric essential thrombocythaemia really myeloproliferative neoplasms? Analysis of a large cohort. Br J Haematol 169: 584-589. [Crossref]

16. Karow A, Nienhold R, Lundberg P, Peroni E, Putti MC, et al. (2015) Mutational profile of childhood myeloproliferative neoplasms. Leukemia 29: 2407-2409.[Crossref]

17. Fu R, Liu D, Cao Z, Zhu S, Li H, et al. (2016) Distinct molecular abnormalities underlie unique clinical features of essential thrombocythemia in children. Leukemia 30: 746749. [Crossref]

18. Kucine N, Viny AD, Rampal R, Berger M, Socci N, et al. (2016) Genetic analysis of five children with essential thrombocytosis identifies mutations in cancer-associated genes with roles in transcriptional regulation. Haematologica 101: e237-e239. [Crossref]

19. Nelson ND, Marcogliese A, Bergstrom K, Scheurer M, Mahoney D, et al. (2016) Thrombopoietin Measurement as a Key Component in the Evaluation of Pediatric Thrombocytosis. Pediatr Blood Cancer 63: 1484-1487.[Crossref]

20. Hermouet S, Bigot-Corbel E, Gardie B (2015) Pathogenesis of Myeloproliferative Neoplasms: Role and Mechanisms of Chronic Inflammation. Mediators Inflamm 2015: 145293.[Crossref]

21. Barbui T, Thiele J, Vannucchi AM, Tefferi A (2015) Rationale for revision and proposed changes of the WHO diagnostic criteria for polycythemiavera, essential thrombocythemia and primary myelofibrosis. Blood Cancer J 5: e337. [Crossref]

Copyright: (C)2016 Kaouthar A. This is an open-access article distributed under the terms of the Creative Commons Attribution License, which permits unrestricted use, distribution, and reproduction in any medium, provided the original author and source are credited. 